\title{
Conversion of Typical to "Atypical" Atrioventricular Nodal Reentrant Tachycardia After Radiofrequency Catheter Modification of the Atrioventricular Junction
}

\author{
Jonathan J. Langberg, MD, Yoon-Nyun Kim, MD, Rajiva Goyal, MD, William Kou, MD, \\ Hugh Calkins, MD, Joao Sousa, MD, Rafel El-Atassi, MD, and Fred Morady, MD
}

\begin{abstract}
Typical atrioventricular (AV) nodal reentry tachycardia (AVNRT) is characterized by anterograde activation over a slowly conducting pathway and by retrograde activation through a rapidly conducting pathway. Preliminary reports suggest that radiofrequency catheter modification can eliminate typical AVNRT whlle preserving anterograde conduction. Radiofrequency catheter modification was used to treat 88 patients with typical AVNRT. After baseline electrophysiologic evaluation, the ablation catheter was positioned proximal and superior to the site of maximal His deflection. Radiofrequency energy was applied until there was significant attenuation of retrograde conduction, and elimination of AVNRT inducibility. Eighty-one patients were successfully treated and form the basis of this report.
\end{abstract}

A new paroxysmal supraventricular tachycardia with RP > PR interval was induced at electrophysiologic testing after successful ablation in 9 patients (11\%). Mean atrial-His activation time was $140 \pm 31 \mathrm{~ms}$, and the ventriculoatrial activation time was $170 \pm 46$ ms. This arrhythmia was induced only with ventricular pacing during isoproterenol infusion and appeared to be mediated by AV nodal reentry. New retrograde dual AV nodal physiology after modification was more frequent in patients with atypical tachycardia than in those without ( 4 of 9 vs 2 of 72; p <0.0001). Although none of the patients were treated, only 1 of 9 had an episode of spontaneous atypical tachycardia during a mean follow-up of 12 months.

Results of this study confirm that typical AVNRT can be rendered noninducible without the complete destruction of reentrant pathways. Because induction of "atypical" AVNRT was not predictive of spontaneous arrhythmia recurrence, it should not be an indication for additional ablation sessions or long-term drug therapy.

(Am J Cardiol 1992;69:503-508)

From the Department of Internal Medicine, Division of Cardiology, University of Michigan Medical Center, Ann Arbor, Michigan. Manuscript received October 14, 1991; revised manuscript received and accepted October 24, 1991.

Address for reprints: Jonathan J. Langberg, MD, University of Michigan Medical Center, 1500 East Medical Center Drive, B1 F245, Ann Arbor, Michigan 48109-0022.
$\mathrm{T}$ achycardia due to atrioventricular (AV) nodal reentry (AVNRT) needs 2 nodal or perinodal pathways, differentiated on the basis of their relative conduction times. ${ }^{1}$ Typical AVNRT is characterized by anterograde conduction over the "slow" pathway and by retrograde conduction over the "fast" pathway, and accounts for approximately $50 \%$ of patients with paroxysmal supraventricular tachycardia. Atypical AVNRT, in which there is retrograde conduction over the slow pathway, and anterograde conduction over the fast pathway, is much less frequent, accounting for $<1 \%$ of paroxysmal supraventricular tachycardias in most series. ${ }^{2,3}$ Preliminary reports suggest that catheter modification of the $\mathrm{AV}$ node using radiofrequency energy can eliminate AVNRT while preserving anterograde conduction..$^{4-6}$ However, the anatomic substrate for nodal reentry remains incompletely defined. This report describes the occurrence of a new type of tachycardia after successful ablation of typical AVNRT. This tachycardia has the appearance of atypical AVNRT, with a PR interval shorter than the RP interval. The characteristics and clinical significance of this "atypical" tachycardia, and the possible mechanisms by which it occurs are described.

\section{METHODS}

Patients and ablative procedure: Between August 1989 and November 1990, 88 patients (29 men and 59 women, mean age $50 \pm 18$ years) were referred to the University of Michigan Medical Center for treatment of typical AVNRT. This cohort was described in part in previous reports. ${ }^{4,5}$ Patients had been symptomatic for a mean of $18 \pm 13$ years. The ablation procedure was approved by the institutional review board, and all patients gave informed, written consent. All patients underwent a baseline electrophysiologic test to define anterograde and retrograde AV conduction and refractoriness, and to confirm the presence of typical AV nodal reentry tachycardia, using previously described techniques. ${ }^{7}$ The following criteria were sought to support the diagnosis of AV nodal reentry: (1) tachycardia induction associated with a critical degree of prolongation of the atrial-His ( $\mathrm{AH})$ interval, and (2) atrial activation during tachycardia that was coincident with or closely $(<50 \mathrm{~ms})$ followed ventricular activation. Other findings suggestive of AVNRT were the presence of dual AV nodal physiology (discontinuous AV nodal function curves) and tachycardia termination with a premature 
TABLE I Baseline Clinical and Electrophysiologic

Characteristics of Patients With and Without "Atypical" AVNRT After Catheter Ablation

\begin{tabular}{|c|c|c|c|}
\hline & $\begin{array}{l}\text { Atypical AVNRT } \\
\text { After Ablation }\end{array}$ & $\begin{array}{c}\text { No Atypical } \\
\text { AVNRT } \\
\text { After Ablation }\end{array}$ & $p$ Value \\
\hline No. of pts. & 9 & 72 & \\
\hline Mean age (yr) & $52 \pm 18$ & $50 \pm 19$ & NS \\
\hline Men/women & $1 / 8$ & $28 / 44$ & NS \\
\hline $\begin{array}{l}\text { Duration of symptoms } \\
\text { from AVNRT (yr) }\end{array}$ & $12 \pm 10$ & $18 \pm 14$ & NS \\
\hline Typical AVNRT CL (ms) & $314 \pm 40$ & $387 \pm 77$ & 0.02 \\
\hline AV block CL (ms) & $310 \pm 60$ & $365 \pm 79$ & NS \\
\hline VA block CL (ms) & $323 \pm 79$ & $359 \pm 101$ & NS \\
\hline $\begin{array}{l}\text { Anterograde dual AV } \\
\text { nodal physiology }\end{array}$ & 5 & 51 & NS \\
\hline \multicolumn{4}{|c|}{$\begin{array}{l}\text { AV block } \mathrm{CL}=\text { atrioventricular Wenckebach block cycle length; AVNRT }= \\
\text { atrioventricular nodal reentry; } N S=\text { not significant; } \mathrm{VA} \text { block } \mathrm{CL}=\text { ventriculoatrial } \\
\text { Wenckebach block cycle length. }\end{array}$} \\
\hline
\end{tabular}

ventricular complex that did not result in activation of the atria. An electrode catheter was not introduced into the coronary sinus, and detailed mapping of the sequence of retrograde activation was not performed. No patient had atypical AV nodal reentry induced before catheter ablation.

The technique for catheter ablation, as previously described, ${ }^{4}$ was performed with an electrosurgical unit (Radionics RFG 3-B, Watertown, MA) that delivered a constant, unmodulated sine wave output at $350 \mathrm{kHz}$. A large-tip ( 3 or $4 \mathrm{~mm}$ in length) electrode catheter was positioned slightly proximal and superior to the site of the maximal His bundle deflection. Recordings from the ablation site typically had an atrial-to-ventricular electrogram ratio $\geq 1$, and a His amplitude $<100 \mu \mathrm{V}$. A mean of $14 \pm 5 \mathrm{~W}$ of radiofrequency power was applied between the distal electrode of the ablation catheter and an indifferent skin electrode. Ablation was continucd until there was $>50 \%$ prolongation in the $\mathrm{PR}$ interval or

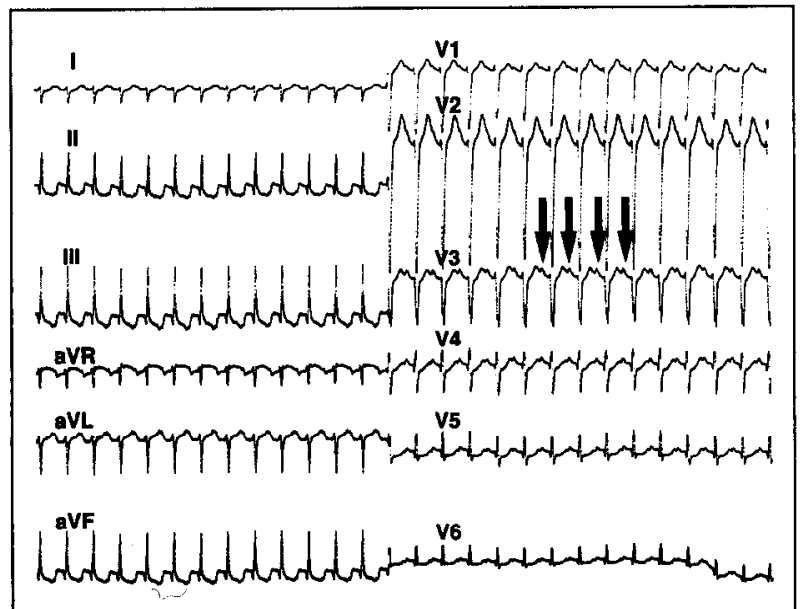

FIGURE 1. Twetve-lead electrocardiogram during atypical atuioventricular nodal reentry induced after radifofrequency catheter ablation. Note chort PR interval (arrows) and superior P-wave axis. ventriculoatrial conduction time, or both, and typical AVNRT could no longer be induced.

Eighty-one patients had a successful outcome, defined as persistent elimination of typical AVNRT inducibility with preservation of AV conduction, and form the basis of this report. After a successful ablation, electrophysiologic testing was performed before and during isoproterenol infusion at a dose sufficient to increase the heart rate by $\geq 20 \%$. Complete electrophysiologic testing with evaluation of $\mathrm{AV}$ conduction was repeated 2 to 4 days and again at 3 months after the ablation procedure in all patients. At follow-up testing, patients who had a new supraventricular tachycardia characterized by an $\mathrm{AH}<$ the His-atrial (HA) interval were considered to have "atypical" tachycardia. Patients with atypical supraventricular tachycardia induced after ablation had complete electrophysiologic evaluations aimed at characterizing the arrhythmia mechanism, including both atrial and ventricular extrastimulus testing during tachycardia.

Data analysis: Results are expressed as mean \pm 1 standard deviation. Characteristics of patients with and without atypical tachycardia were compared by analysis of variance and chi-square analysis. The Student's $t$ test for paired data was used to compare features of supraventricular tachycardia and AV nodal function before and after ablation. A p value $<0.05$ was considered significant.

\section{RESULTS}

Nine of $81(11 \%)$ patients successfully treatcd with radiofrequency catheter ablation had new, "atypical" AV nodal reentry induced during the follow-up electrophysiologic study (Figure 1). The arrhythmia was induced immediately after radiofrequency modification in 3 patients and at the early ( 2 to 4 days) restudy in 4 . Atypical tachycardia was induced for the first time at the late ( 3 months) follow-up test in 3 patients. There were no differences in mean age, sex distribution and duration of symptoms between patients with (group I) and without (group II) atypical AV nodal reentry after ablation (Table I).

Electrophysiologic characteristics of atypical supraventricular tachycardia induced during follow-up evaluation: In all group I patients, atypical supraventricular tachycardia was induced only by ventricular overdrive pacing or programmed stimulation, or both, during isoproterenol infusion (Figure 2). Single atypical echo beats were induced in only 1 patient in the baseline state during ventricular extrastimulation. Initiation of the tachycardia appeared to be dependent on achieving a critical degree of delay in retrograde conduction. In 4 patients, new retrograde dual AV nodal physiology (defined as $\geq 50 \mathrm{~ms}$ increase in ventriculoatrial activation time after $10 \mathrm{~ms}$ decrease in the coupling interval of the ventricular extrastimulus) was observed after ablation (Figure 3). In distinct contrast to the baseline findings before ablation, none of these patients had supraventricular tachycardia induced with atrial overdrive pacing or extrastimulation. Characteristics of the arrhythmia are 
summarized in Table II. Mean tachycardia cycle length was $357 \pm 51 \mathrm{~ms}$. Mean AH activation time was $140 \pm$ $31 \mathrm{~ms}$, and ventriculoatrial time was $170 \pm 46 \mathrm{~ms}$.

During ventricular pacing, retrograde conduction was decremental and atrial septal activation preceded high right atrial activation in all cases. Tachycardia was reproducibly terminated with ventricular overdrive pacing in 7 of 9 patients. In 1 patient, a ventricular premature stimulus interrupted the tachycardia without subsequent retrograde atrial activation, and in another, spontaneous termination of the arrhythmia after atrial activation was seen.

AV nodal function in group 1 during isoproterenol infusion before and after ablation at the time of induction of atypical AV nodal reentry are compared in Table II. As with the overall population, radiofrequency ablation produced an increase in the AH interval in sinus rhythm from $69 \pm 12$ to $147 \pm 26 \mathrm{~ms}$. Despite the increase in conduction time, there was no change in anterograde AV Wenckebach block cycle length. In contrast, retrograde conduction was significantly attenuated, as reflected by an increase in the ventriculoatrial block cycle length from $257 \pm 32$ to $344 \pm 47 \mathrm{~ms}$ (p $<0.01$ ). The AH interval during atypical AV nodal reentry was a mean of $67 \mathrm{~ms}<\mathrm{AH}$ during atrial overdrive pacing at a comparable cycle length of $350 \mathrm{~ms}$.

Comparison of patients with and without atypical atrioventricular modal reentrant tachycardia: The cycle length of AVNRT induced during the baseline electrophysiologic test was shorter for group I (314 $\pm 40 \mathrm{~ms})$ than II ( $387 \pm 77 \mathrm{~ms} ; \mathrm{p}=0.02)$. Anterograde and retrograde AV nodal Wenckebach cycle lengths and the frequency of anterograde dual AV nodal physiology were the same for both groups (Table I).

The number of radiofrequency applications, and the mean voltage, current and duration of each applica-

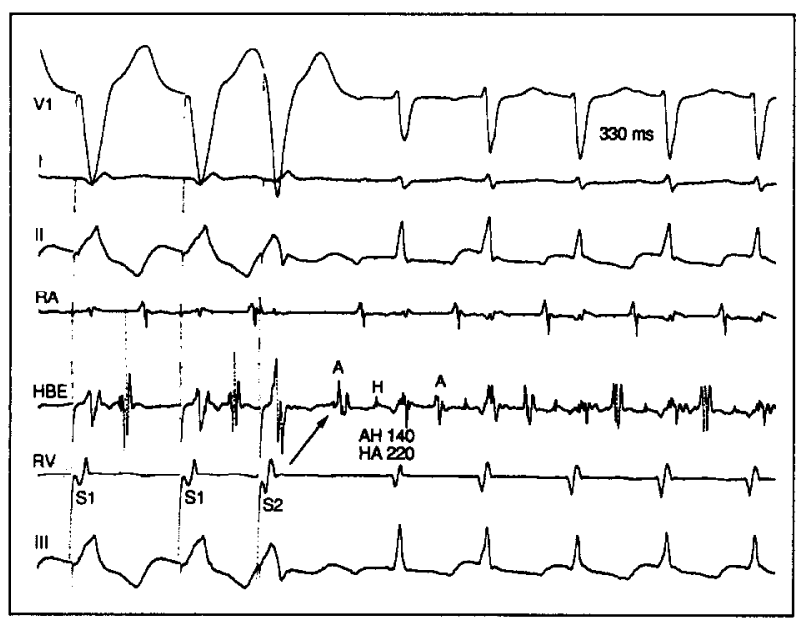

FIGURE 2. Induction of atypical atrioventricular nodal reentry with ventricular extrastimulation. Note initiation of tachycardila with prolongation in ventriculoatrial activation time (arrow). As was characteristic of all group I patients, atrial-His (AH) activation time was less than that of His-atrial (HA).

HBE = His bundle electrogram; RA = endocardial electrogram trom high right atrium; RV = right ventrictar endocardial recording.
TABLE I Changes Produced by Ablation in Nine Patients with New "Atypical" AVNRT

$\begin{array}{cc}\text { Before } & \text { After } \\ \text { Ablation } & \text { Ablation } \\ & p \text { Value }\end{array}$

Characteristics of Induced AVNRT During Isoproterenol Infusion

\begin{tabular}{|lccc|}
\hline $\mathrm{CL}$ (ms) & $314 \pm 40$ & $357 \pm 51$ & 0.05 \\
$\mathrm{AH}(\mathrm{ms})$ & $237 \pm 31$ & $140 \pm 31$ & 0.01 \\
$\mathrm{VA}(\mathrm{ms})$ & $16 \pm 9$ & $170 \pm 46$ & 0.01
\end{tabular}

Electrophysiologic Characteristics During Isoproterenol Infusion

$\begin{array}{lrrc}\text { AV block CL (ms) } & 266 \pm 42 & 257 \pm 32 & \text { NS } \\ \text { VA block CL (ms) } & 260 \pm 31 & 344 \pm 47 & 0.01 \\ \text { AH interval in sinus } & 69 \pm 12 & 147 \pm 26 & 0.01 \\ \quad \begin{array}{l}\text { rhythm (ms) } \\ \text { AH interval during AOD } \\ \quad(350 \mathrm{~ms})\end{array} & 118 \pm 62 & 207 \pm 64 & 0.05\end{array}$

$\mathrm{AH}=$ atrio-His interval; $\mathrm{AOD}=$ atrial overdrive pacing; $\mathrm{CL}=$ cycle length; $\mathrm{VA}=$ ventriculoatrial interval; other abbreviations as in Table I.

tion were similar for the 2 groups (Table III). The amplitudes of the atrial, His and ventricular electrograms at the site resulting in successful ablation of typical AVNRT were also similar for the 2 groups.

Atrioventricular nodal function in patients with and without atypical reentry after successful modification are compared in Table IV. There were no differences in anterograde or retrograde block cycle lengths or effective refractory periods between the 2 groups. Retrograde conduction was present in all 9 patients in group $\mathrm{I}$, and in 37 of 72 in group II $(\mathrm{p}=0.0006)$. There was a trend toward shorter ventriculoatrial conduction times at a paced cycle length of $400 \mathrm{~ms}$ in group I than in II (162 \pm 10 vs $247 \pm 62 \mathrm{~ms} ; \mathrm{p}=0.066$ ). Anterograde dual AV nodal physiology was not seen in any group I patient and was present in 9 group II patients after suc-

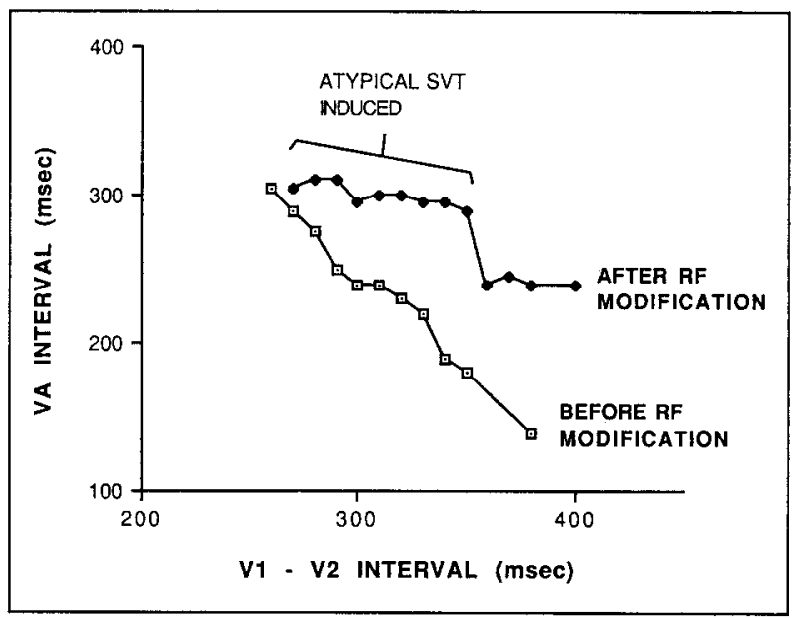

FIGURE 3. Retrograde atrioventriculer nodal function curves before and after radiofrequency (RF) modification in patient with atypical aupraventricular tachycardia (SVT). Note presence of dual phydology after but not before procedire. Atypical supraventricular tachycardila was consistenthy induced with coupling intervals associated with conduction over retrograde slow pattmway. VA = ventriculoatrial; V1 = ventricular difve train; V2 = ventricular extrastimulus. 


\begin{tabular}{|c|c|c|}
\hline \multicolumn{3}{|c|}{$\begin{array}{l}\text { TABLE II Ablation Parameters in Patients With and Without } \\
\text { "Atypical" AVNRT }\end{array}$} \\
\hline & $\begin{array}{l}\text { With Atypical } \\
\text { AVNRT After } \\
\text { Ablation }\end{array}$ & $\begin{array}{l}\text { No Atypical } \\
\text { AVNRT After } \\
\text { Ablation }\end{array}$ \\
\hline \multicolumn{3}{|c|}{ Radiofrequency Energy Delivery Parameters } \\
\hline $\begin{array}{l}\text { No. of RF applications } \\
\text { Voltage (V) } \\
\text { Current (amp) } \\
\text { Duration (sec) }\end{array}$ & $\begin{aligned} 7 & \pm 4 \\
42 & \pm 6 \\
0.37 & \pm 0.044 \\
49 & \pm 21\end{aligned}$ & $\begin{aligned} 7 & \pm 6 \\
45 & \pm 12 \\
0.35 & \pm 0.11 \\
52 & \pm 46\end{aligned}$ \\
\hline \multicolumn{3}{|c|}{ Electrogram Amplitudes at the Effective Site } \\
\hline $\begin{array}{l}\text { Atrial (mV) } \\
\text { His (mV) } \\
\text { Ventricular (mV) }\end{array}$ & $\begin{array}{c}2.2 \pm .46 \\
0.086 \pm 0.082 \\
0.92 \pm 0.68\end{array}$ & $\begin{aligned} 1.7 & \pm 0.7 \\
0.066 & \pm 0.05 \\
0.88 & \pm 0.70\end{aligned}$ \\
\hline
\end{tabular}

cessful modification ( $p=$ not significant). New retrograde dual physiology occurred in 4 group I and in 2 group II patients $(p=0.0001)$ after the procedure.

Follow-up of patients with atypical atrioventricular nodal reentrant tachycardia: No patient with atypical AVNRT after ablation received antiarrhythmic therapy or additional ablation sessions. One patient developed a spontaneous, sustained episode of atypical AVNRT 4 weeks after ablation. Therapy with verapamil (240 $\mathrm{mg}$ /day) was initiated, but was discontinued after 2 months because of intractable side effects. Repeat electrophysiologic testing at that time showed no retrograde conduction or inducible tachycardia before or during isoproterenol infusion. This patient has been free of arrhythmia recurrence for 13 months without therapy.

The remaining 8 patients have been followed for 12 \pm 3 months. None have had symptomatic tachycardias. None of the 6 patients who had atypical AVNRT during their initial hospitalization (either immediately after modification or at the early restudy) had inducible tachycardia at the time of late restudy (3 months). Retrograde conduction was no longer present in 3 of these patients during the late restudy.

\section{DISCUSSION}

Main findings: A ncw paroxysmal supraventricular tachycardia with a long RP interval was induced after successful radiofrequency catheter ablation of typical AVNRT in 9 of $81(11 \%)$ patients. The baseline cycle length of the typical AVNRT was slightly shorter in patients who went on to develop atypical tachycardia than in those who did not. Otherwise, there were no differences in baseline clinical, electrophysiologic or ablation parameters between the 2 groups.

Atypical tachycardia was inducible only by ventricular pacing during isoproterenol infusion and appeared to be mediated by $A V$ nodal reentry. New retrograde dual AV nodal physiology was more frequent in patients with atypical reentry than in those without tachycardia after ablation. Although no patient was treated with antiarrhythmic medications, only 1 of 9 had an episode of spontaneous atypical tachycardia during a mean fol-

\begin{tabular}{|c|c|c|c|}
\hline & $\begin{array}{l}\text { Group I: } \\
\text { Atypical } \\
\text { AVNRT } \\
(n=9)\end{array}$ & $\begin{array}{l}\text { Group II: } \\
\text { No Atypical } \\
\text { AVNRT } \\
(n=72)\end{array}$ & $p$ Value \\
\hline $\begin{array}{l}\text { AH interval in sinus } \\
\text { rhythm }\end{array}$ & $147 \pm 26$ & $136 \pm 55$ & NS \\
\hline $\begin{array}{l}\text { VA interval during ventric- } \\
\text { ular pacing (CL } 400 \\
\text { ms) }\end{array}$ & $162+10$ & $247+76$ & 0.066 \\
\hline $\begin{array}{l}\text { Maximal VA interval dur- } \\
\text { ing ventricular overdrive } \\
\text { pacing }\end{array}$ & $244 \pm 39$ & $252 \pm 64$ & NS \\
\hline AV block cycle length & $257 \pm 32$ & $300 \pm 76$ & NS \\
\hline VA block cycle length & $344 \pm 47$ & $349 \pm 67$ & NS \\
\hline AVNERP & $220 \pm 28$ & $236 \pm 43$ & NS \\
\hline VA ERP & $263 \pm 85$ & $269 \pm 87$ & NS \\
\hline VA conduction & $9 / 9$ & $37 / 72$ & 0.006 \\
\hline $\begin{array}{l}\text { Anterograde dual physiol- } \\
\text { ogy }\end{array}$ & $0 / 9$ & $9 / 72$ & NS \\
\hline $\begin{array}{l}\text { Retrograde dual physiol- } \\
\text { ogy }\end{array}$ & $4 / 9$ & $2 / 72$ & 0.0001 \\
\hline
\end{tabular}

low-up of 12 months. Therefore, induction of atypical AV nodal reentry after radiofrequency ablation of typical AVNRT appears to be of little clinical significance.

Comparison with previous studies: Several features of this novel arrhythmia suggest that it was mediated by AV nodal reentry rather than atrial tachycardia or an accessory AV connection. The tachycardia was reproducibly induced with critically timed ventricular extrastimulation, as has been described in patients with spontaneous retrograde dual AV nodal physiology. ${ }^{8}$ Termination of the tachycardia with a ventricular premature beat that did not excite the atrium excludes its participation in the reentry circuit. Spontaneous termination after atrial activation also argues against an atrial arrhythmia. There was no evidence of extranodal accessory AV connections, with decremental retrograde atrial activation in all cases.

Haissaguerre et al $^{9}$ recently described the follow-up of 42 patients after direct-current shock ablation for $\mathrm{AV}$ nodal reentry. Four of 26 patients (15\%) undergoing late (4.7 \pm 6 months after ablation) electrophysiologic testing had single atypical AV nodal echo beats induced. Apparently none of these patients had sustained tachycardia, but it is not clear how many had repeat testing during isoproterenol infusion.

Observations relating to the site of ablative injury: Several features of patients who developed atypical AVNRT may have implications relevant to the location of ablative injury. The $\mathrm{AH}$ interval during atrial pacing was markedly prolonged after ablation. In contrast, the AH interval during atypical AVNRT was relatively short. The AH interval during atrial pacing is the sum of conduction times in the proximal common pathway and the AV node itself, whereas during tachycardia, the AH interval is the difference between these conduction 
times. ${ }^{10}$ Therefore, the conduction delay that was present during atrial pacing was due to slowing proximal to the reentry circuit in the upper common pathway (Figure 4A). This evidence of an upper common pathway strongly suggests that atrial tachycardia was not responsible for the atypical tachycardia induced after ablation.

Anterograde AV nodal block cycle length and refractoriness did not change despite the marked increase in conduction time. A similar pattern was observed in an animal study when ablative injury involved the approaches to the node with relative sparing of the more distal NH region." "Some animals in that study had progressive attenuation of $\mathrm{AV}$ nodal function in the weeks after ablation, presumably as the result of fibrosis and scar formation. A similar process may account for the loss of retrograde conduction in 4 of 9 patients with atypical AV nodal reentry early after ablation.

Possible mechanisms of atypical reentry after ablation: Possible mechanisms for reentry after ablation are diagrammed in Figure 4 . The arrhythmia may represent the original, typical AV nodal reentry with superimposed proximal common pathway delay. Although retrograde conduction in the reentry circuit remains fast, slow conduction in the proximal common pathway would produce a long ventriculoatrial interval. This mechanism seems unlikely because it does not account for the significant slowing of tachycardia rate after ablation and for the inducibility of paroxysmal supraventricular tachycardia by ventricular pacing after ablation but not at baseline.

Ablative injury may have resulted in prolongation of refractoriness in the fast pathway. This could allow selective retrograde block in the fast pathway during ventricular pacing and initiation of atypical AVNRT (retrograde conduction through the slow pathway, and anterograde over the fast pathway). The trend toward a shorter ventriculoatrial time at slower paced rates, and the emergence of retrograde dual AV nodal physiology in 4 of 9 patients is consistent with this hypothesis. The disappearance of retrograde conduction in 4 patients who initially had atypical tachycardia also supports the notion that it was mediated by a damaged fast pathway.
An ablation-induced increase in fast pathway conduction time could account for many of the observations. Although the circuit would be the same as before ablation, retrograde activation would be delayed. The resultant slowing in tachycardia rate might be expected to shorten anterograde conduction time and the $\mathrm{AH}$ interval.

Finally, destruction of the fast pathway might unmask a third pathway capable of mediating retrograde conduction, albeit more slowly. Triple pathways have been described, ${ }^{12,13}$ and such a pathway may be concealed during the baseline evaluation. McGuire et al ${ }^{14}$ recently described a small cohort of patients with 2 types of AV nodal recntry. In addition to typical AV node reentry, they also had a second type of tachycardia with earliest atrial activation near the os of the coronary sinus. As with the patients in the current study, the atypical reentry was characterized by a slower rate, shorter $\mathrm{AH}$ intervals and longer ventriculoatrial activation time. They hypothesized that these patients had 2 slow AV nodal pathways located posteriorly, 1 of which was capable of serving at the retrograde limb of a "slow-slow" tachycardia circuit (Figure 3B).

This study is limited by the absence of coronary sinus recordings or retrograde activation times from other sites on the interatrial septum. These data may have clarified whether the atypical reentry was mediated by pathways that were anatomically distinct from those responsible for the initial, typical tachycardia.

Clinical implications: Previous reports of patients treated by either catheter ${ }^{4-6.16}$ or operative ${ }^{17-18}$ ablation noted control of AVNRT despite persistence of retrograde AV nodal conduction, dual AV nodal physiology and AV nodal echo beats. The results of this study confirm that typical AVNRT can be rendered noninducible without complete destruction of intra- or perinodal reentrant pathways.

Elimination of typical AVNRT was the end point for radiofrequency catheter modification of the AV junction in this series. More than $10 \%$ of patients deemed successfully treated had atypical reentry induced after ablation. Sustained tachycardia could only
FIGURE 4. Possible mechanisms of atypical atrioventricular (AV) nodal reentry after ablation. A, continued typical (up fast-down slow) tachycardia with superimposed ablation-induced upper common pathway (UCP) delay. This proximal delay would prolong retrograde atrial activation time. $B$, ablation-induced increase in fast pathway refractoriness resulting in seloctive retrograde fast pathway block and initiation of "true atypical" (up slow-down fast) reentry. $C$, slowing in retrograde fast pathway produced by ablative injury causes increased retrograde atrial activation time and slowing of tachycardia rate. Slower rate produces decrease in anterograde ventricular activation time. D, ablation interrupts retrograde fast pathway, unmasking a second, slower retrograde pathway. $A=$ atrium; $V$ = ventricle.

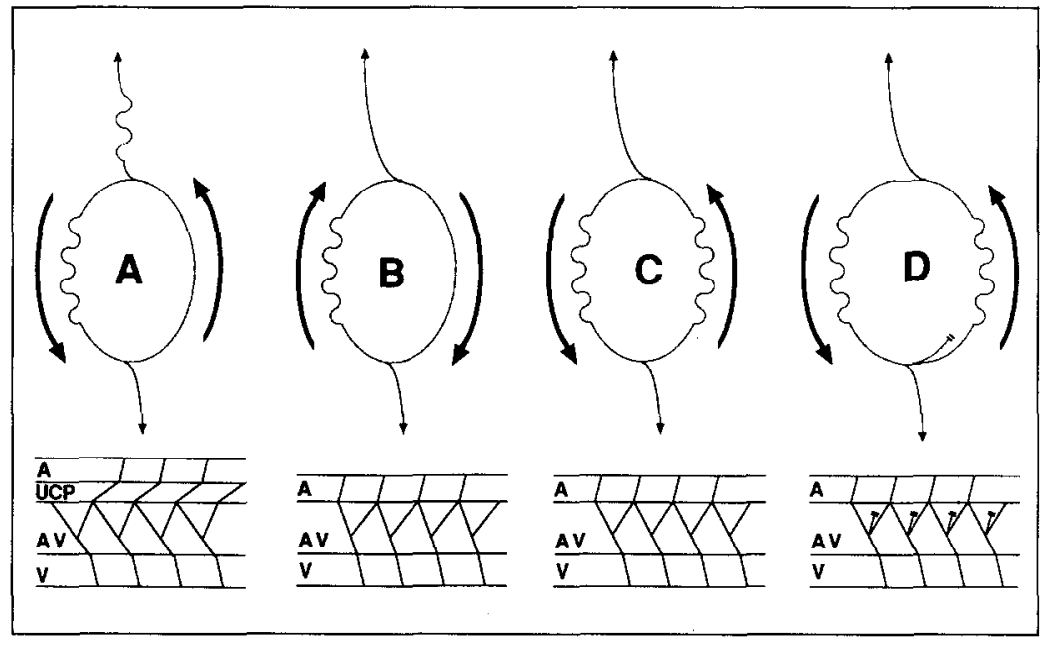


be induced during isoproterenol infusion owing to significant attenuation of retrograde conduction. This may account for the low incidence of spontaneous atypical reentry and suggests that induction of this tachycardia should not be an indication for additional ablation sessions or long-term antiarrhythmic therapy.

\section{REFERENCES}

1. Denes P, Wu D, Dhingra RC, Chuguimia R, Rosen KM. Demonstrations of dual AV pathways in patients with paroxysmal supraventricular tachycardia. Circulation 1973;48:549-555.

2. Wu D, Denes $P$, Amat-Y-Leon F, Dhingra $R$, Wyndham CRC, Bauerfeind $R$, Latif $P$, Rosen KM. Clinical, electrocardiographic and electrophysiologic observations in patients with paroxysmal supraventricular tachycardia. Am J Cardiol 1978:41:1045-1051.

3. Brugada $P$, Wellens HJJ. Electrophysiology, mechanisms, diagnosis and treatment of paroxysmal recurrent atrioventricular nodal reentrant tachycardia. In: Surawicz B, Reddy CP, Prystowsky EN, eds. The Tachycardias. Boston: Martinus Nijhoff, 1984:131-157.

4. Lee MA, Morady F, Kadish A, Schamp DJ, Chin MC, Scheinman MM Griffin JC, Lcsh MD, Pcderson D, Goldberger J, Calkins H, de Buitleir M, Kou WH, Rosenheck S, Sousa J, Langberg JJ. Catheter modification of the atrioventricular junction with radiofrequency energy for control of atrioventricular nodal reentry tachycardia. Circulation 1991;83: in press.

5. Calkins H, Sousa J, El-Atassi R, Rosenheck S, de Buitleir M, Kou WH, Kadish AH, Langberg JJ, Morady F. Diagnosis and cure of the Wolff-ParkinsonWhite syndrome or paroxysmal supraventricular tachycardias during a single electrophysiologic test. N Engl J Med 1991;324:1612-1618

6. Goy JJ, Fromer M, Schlaepfer J, Kappenberger L. Clinical efficacy of radiofrequency current in the treatment of patients with atrioventricular node reentran tachycardia. J Am Coll Cardiol 1990;16:418-423.

7. Epstein LM, Scheinman MM, Langberg JJ, Chilson D, Goldberg HR, Griffin
JC. Percutaneous catheter modification of the atrioventricular node. A potential cure for atrioventricular nodal reentrant tachycardia. Circulation 1989;80: $757-768$

8. Wu D, Denes P, Amat-Y-Leon F, Wyndham CRC, Dhingra R, Rosen KM. An unusual variety of atrioventricular reentry due to retrograde dual atrioventricular nodal pathways. Circulation 1977;56:50-59.

9. Haissaguerre $M$, Warin JF, D'lvernois $C$, Le Metayer PH, Montserrat P. Fulguration of AV nodal tachycardia: results in 42 patients with a mean follow-up of 23 months. PACE 1990;13:2000-2007.

10. Miller JM, Rosenthal ME, Vassallo JA, Josephson ME. Atrioventricular nodal reentrant tachycardia: studies on upper and lower "common pathways." Circulation 1987;75:930-940.

11. Huang SKS, Bharati S, Graham AR, Gorman G, Lev M. Chronic incomplete atrioventricular block induced by radiofrequency catheter ablation. Circulation 1989:80:95i-961.

12. Kuhlkamp V, Haasis R, Seipel L. AV nodal reentrant tachycardia using three different AV nodal pathways. Eur Heart $J$ 1990;1 1:857-862.

13. Sebag C, Chevalier P, Davy JM, Laine JF, Motte G. Triple antegrade nodal pathway in a patient with supraventricular paroxysmal tachycardia. JElectrocardiol 1986;19:85-90

14. McGuire M, Lau KC, Johnson DC, Richards DA, Uther JB, Ross DL. Patients with two types of atrioventricular junctional (AY nodal) reentrant tachycardia. Evidence that a common pathway of nodal tissue is not present above the reentrant circuit. Circulation 1991;83:1232-1246.

15. Haissaguerre M, Warin JF, Lemetayer $P$, Saoudi N, Guillem JP, Blanchot $P$. Closed-chest ablation of retrograde conduction in patients with atrioventricular nodal reentrant tachycardia. $N$ Engl J Med 1989;320:426-433.

16. Ross DL, Johnson DC, Koo CC, Mortensen P, Cooper MJ, Denniss AR, Richards DA, Uther JB. Surgical treatment of supraventricular tachycardia without the Wolff-Parkinson-White syndrome: current indications, techniques and result. In: Brugada P, Wellens HJJ, eds. Cardiac Arrhythmias, Where to Go From Here? Mt. Kisco, NY: Futura, 1987:591-604.

17. Ross DL, Johnson DC, Denniss AR, Cooper MJ, Richards DA, Uther JB. Curative surgery for atrioventricular junctional ("AV nodal") reentrant tachycardia. J Am Coll Cardiol 1985;6:1383-1392.

18. Cox JL, Holman WL, Cain ME. Cryosurgical treatment of atrioventricular node reentrant tachycardia. Circulation 1987:76:1329-1336. 